\title{
RADIOLOGIA FORENSE: COMPARAÇÃO ENTRE OS MÉTODOS DE RAIOS-X E TOMOGRAFIA COMPUTADORIZADA EM CASOS DE HOMICÍDIO POR ARMA DE FOGO
}

Leanderson Luiz de Sá* Instituto Médico Legal André Roquette, Polícia Civil do Estado de Minas Gerais, Belo Horizonte, MG, Brasil Leandro Xavier de Lima Instituto Médico Legal André Roquette, Polícia Civil do Estado de Minas Gerais, Belo Horizonte, MG, Brasil

Diogo Assunção Gonçalves Universidade Federal de Minas Gerais, Belo Horizonte, MG, Brasil

Bárbara Luiza Costa Freitas

Universidade Federal de Minas Gerais, Belo Horizonte, MG, Brasil

\section{FORENSIC RADIOLOGY: COMPARISON BETWEEN X-RAY AND COMPUTED TOMOGRAPHY METHODS IN HOMICIDE CASES BY FIREARMS}

\begin{abstract}
RESUMO
O avanço tecnológico na radiologia tem se revelado cada vez mais importante não só no contexto clínico como, também, na prática forense. A Tomografia Computadorizada (TC) vem sendo utilizada devido à sua exatidão, qualidade de imagem e curto tempo de exame para obtenção de imagens post-mortem em casos como os de homicídio. A técnica tem se mostrado superior à radiologia convencional uma vez que os tomógrafos atuais multislice podem adquirir imagens do corpo inteiro, em poucos segundos, com alta qualidade e sem a sobreposição de estruturas. Estes equipamentos possuem softwares especiais na manipulação da imagem que possibilitam reconstruções 3D facilitando a localização exata do projétil e remoção para o confronto balístico. É possível fazer uma descrição completa de fraturas secundárias, lesões significativas, percurso do projétil deflagrado pela arma de fogo e sua relação com as demais estruturas anatômicas. Este trabalho é um estudo comparativo entre os exames de raios-x e de tomografia computadorizada realizados em um caso de homicídio por arma de fogo conduzido por profissionais do Instituto Médico Legal de Belo Horizonte (IML/BH).
\end{abstract}

PALAVRAS-CHAVE: Radiologia Forense. Tomografia Computadorizada. Homicídio.

\section{ABSTRACT}

Technological advances in radiology have proven to be increasingly important not only in the clinical context but also in forensic practice. Computed tomography (CT) scan has been used due to its accuracy, image quality and short examination time to obtain post-mortem images in cases such as homicide. The technique has been shown to be superior to conventional radiology since the CT scanner has a multislice system that allows acquisition of images of the entire body in a few seconds with high quality and without overlapping structures. These equipments have special software for manipulating the image, such as $3 D$ reconstructions, facilitating the exact location of the projectile. It is possible to make a complete description of secondary fractures, significant injuries, the projectile's path triggered by the firearm and its relationship with the other anatomical structures. The article is a comparative study in the $x$-ray and computed tomography exams performed in a firearm homicide case conducted by professionals from the Belo Horizonte Legal Medical Institute (IML/BH).

KEYWORDS: Forensic Radiology. Computed tomography. Homicide 


\section{INTRODUÇÃo}

A Radiologia Forense tem seu histórico de desenvolvimento praticamente desde o início da descoberta dos raios x em 1895 por Wilhelm Conrad Roentgen. Um dos primeiros eventos que inseriu a Radiologia no rol das ciências forenses decorreu de um homicídio por arma de fogo. Em abril de 1896, no condado de Lancashire, nordeste da Inglaterra ${ }^{1}$, Hargreaves Harley disparou quatro vezes contra a cabeça da esposa. Na ocasião, o professor de física, Arthur Schuster (universidade de Manchester), foi convocado, junto com seus assistentes, para produzirem radiografias do crânio da mulher na tentativa de localizar os projéteis. Foram realizadas, então, as primeiras radiografias que demoraram entre 60 a 70 minutos devido às limitações técnicas da época que mostraram os projéteis de arma de fogo (PAF) no crânio da vítima. A mulher, que havia estado em coma durante vários dias, morreu pouco tempo depois da realização dos exames.

A Tomografia Computadorizada (TC), apesar de um método de aquisição de imagens recente na história da medicina, passou a ser utilizada em estudos post-mortem, com finalidade antropológica, já no ano de 1976, para análise do crânio de uma criança mumificada2. Em seguida, a tomografia passou a ser aplicada em vários países em estudos antropológicos e paleontológicos, em sinergia com o avanço da tecnologia relacionada aos equipamentos. Posteriormente, a técnica passou a interessar, também, a polícia judiciária no âmbito da investigação criminal. 0 primeiro relato de uso de TC em casos envolvendo balística ocorreu em $1977^{2}$. Porém, apenas após o desenvolvimento dos sistemas multislice e as reconstruções 3D (volume rendering techinque - VRT) é que as vantagens se tornaram mais evidentes comparando-se com raios- $x$ convencionais. De fato, foi inicialmente um grupo de pesquisadores japoneses, alemães e suiços, grupo que lançou as bases para as análises de imagens post-mortem culminando no que foi chamado "autopsia virtual" com finalidade de estudo complementar à autopsia tradicional2. Grande parte desses estudos foi baseada, sobretudo, a partir da aplicação de TC em diversos casos como os de vítimas de perfuração por arma de fogo (PAF). Os suíços foram mais longe. Dirigidos por Richard Dirnhofer, do Instituto de Medicina Forense da Universidade de Berna, desenvolveram uma autópsia minimamente invasiva denominada "Virtopsia" que, além da aplicação de TC, utilizaram escaneamento de superfície corporal em 3D e angiografia ${ }^{1}$. Os resultados alcançados tornaram-se a base para trabalhos futuros na Dinamarca, China, Austrália, França e Suécia². No contexto brasileiro, a utilização de equipamentos radiológicos de alto custo em Medicina Legal ainda é incipiente. Muitos Institutos Médicos Legais brasileiros não têm, sequer, um equipamento de raios-x. No ano de 2019, o Instituto Médico Legal de Belo Horizonte (IML/BH), que já dispunha de um setor de radiologia forense bem equipado, adquiriu um tomógrafo. Desde então, a aplicação da técnica passou a integrar a rotina de exames radiológicos auxiliando na elaboração mais ilustrativa de laudos médico-legais. Neste sentido, este estudo visa apresentar um relato de caso de vítima de homicídio por arma de fogo contrapondo a utilização de exames radiológicos convencionais a exames tomográficos.

\section{CASUÍSTICA}

Homicídio por arma de fogo: estudo por raios- $x$ e tomografia

$\mathrm{O}$ presente caso foi conduzido pela equipe do IML/BH no segundo semestre do ano de 2019. Trata-se de um homem caucasiano, com aproximadamente 30 anos de idade, encontrado em via pública com diversas lesões pérfuro contusas. Os projéteis de arma de fogo geram lesões pérfuro contusas que são aquelas causadas por mecanismo de ação que perfura e contunde ao mesmo tempo ${ }^{5}$. As primeiras radiografias deste caso evidenciaram elementos radiopacos condizentes com projéteis. Observa-se, na figura 1, um conjunto de radiografias do caso em tela.

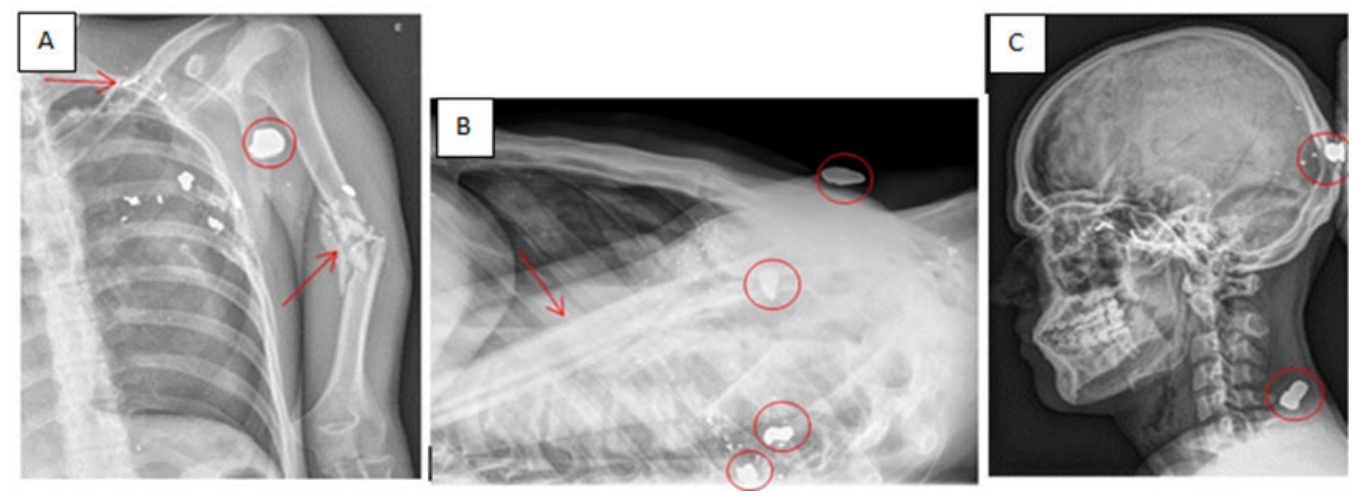

Figura 1: Da esquerda para direita, a imagem "A" mostra um exame em AP de hemitórax esquerdo incluindo região de úmero; setas apontam fraturas e o círculo objeto radiopaco. Em "B", imagem de perfil do tórax; seta demonstra sobreposição de úmero sobre o tórax e círculos destacam objetos radiopacos. Em "C", imagem de perfil do crânio com dois objetos radiopacos circulados (Fonte: Arquivo Radiologia IML/BH). 


\section{DISCUSSÃO}

Após a visualização das primeiras radiografias, o caso foi conduzido pela equipe à sala de Tomografia para a realização de um protocolo padrão que tem sido adotado pela instituição. $O$ tomógrafo utilizado pelo IML/BH é da marca Canon, modelo Alexion de 16 canais. Após o devido acondicionamento do cadáver (Figura 2), foi realizado um protocolo de Tomografia com aquisição de imagens em cortes axiais do vértice do crânio até sínfise púbica (cortes com espessura de $2 \mathrm{~mm}$ ) utilizando algoritmos de reconstrução para partes moles e tecido ósseo. Como costu- meiramente há presença de sangue e outros fluidos, os corpos precisam ser acondicionados em invólucros de modo que não contaminem a mesa do equipamento. $O$ transporte e colocação do cadáver sobre a mesa é complexo e, geralmente, necessita de dois profissionais para tal função. Usualmente os profissionais que manipulam o cadáver são um técnico em radiologia e um auxiliar de necropsia. 0 manuseamento do equipamento fica a cargo de um terceiro servidor (Tecnólogo ou Técnico em Radiologia Forense) ou, por vezes, pelo profissional que conduziu o corpo até o tomógrafo.

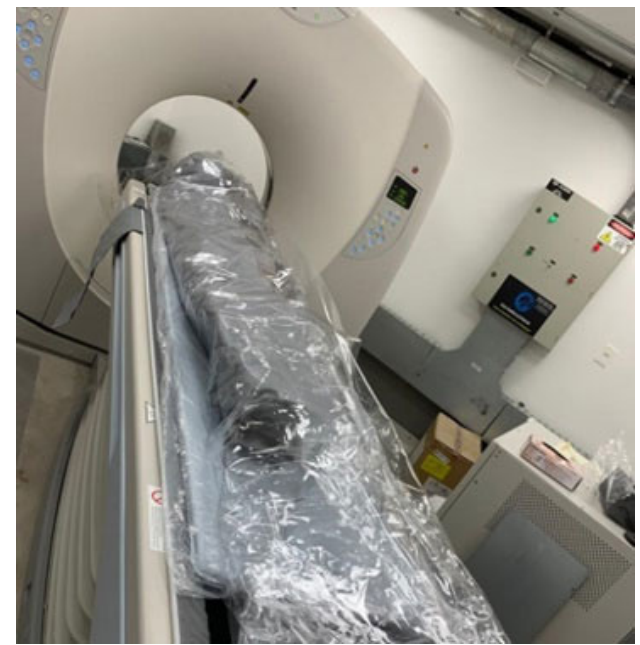

Figura 2: Cadáver devidamente acondicionado em saco plástico para evitar contaminação do equipamento por sangue e fluidos corporais. Esse procedimento auxilia na preservação do equipamento. Contudo, necessita de, no mínimo, dois servidores que são, geralmente, auxiliares de necropsia (Fonte: Arquivo do setor de Radiologia Forense IML/BH).

Após a obtenção das imagens, foram realizadas reconstruções multiplanares nos planos coronal e sagital e uma série de reconstruções em 3D (VRT) com diversos filtros para evidenciar as lesões e os projéteis. Na figura 3, é possível observar a disposição dos projéteis e fragmentos na região do tórax, pescoço e crânio do periciado. Observou-se que o posicionamento do cadáver não ficou adequado devido à rigidez cadavérica, ocasionando inclinação do crânio para a esquerda. A aplicação dos filtros permitiu observar mais claramente a disposição dos projéteis e fragmentos em cor dourada.
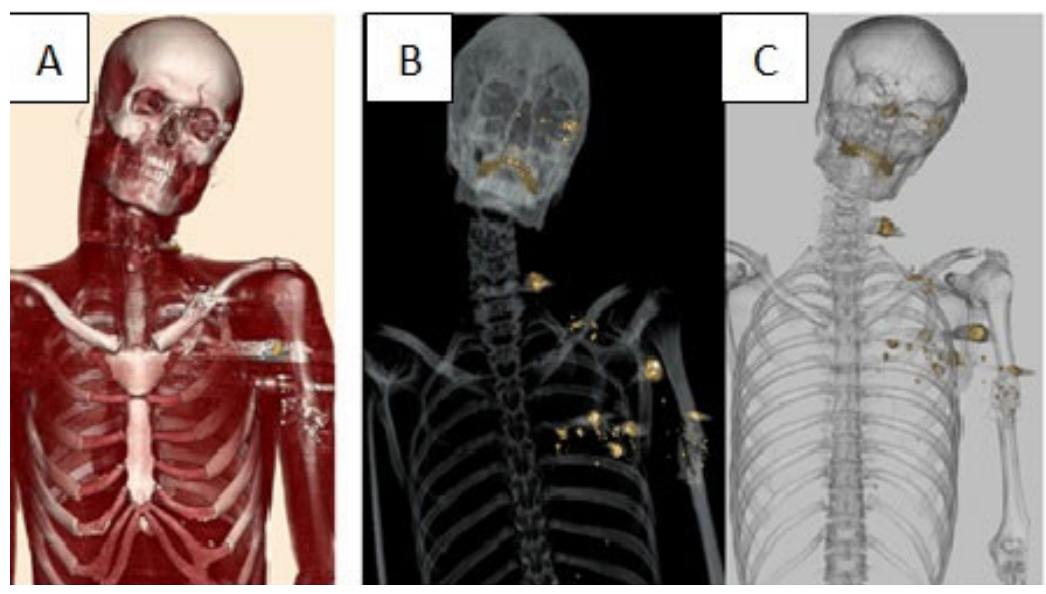

Figura 3: Reconstruções tomográficas pós aquisição de imagens. Em "A", uma reconstrução do vértice do crânio ao gradil costal inferior com exibição de filtros de tecido muscular, ossos e objetos metálicos sobrepostos. Na imagem "B", apresentou-se a mesma sessão com alteração de filtros (uma sobreposição de filtros para objetos metálicos com radiografia). Em "C", novamente a mesma sessão com sobreposição de filtros de transparência com objetos metálicos (Fonte: Arquivo do setor de Radiologia Forense IML/BH ). 
As três reconstruções demonstradas na figura 3 incluíram combinações de filtros e sobreposições de tecidos evidenciando objetos metálicos que apareceram em coloração dourada. Foram excluídas das imagens região de abdome, pelve e membros inferiores, pois não havia lesões nestas regiões. O óbito foi atestado posteriormente como politrauma pérfuro contuso em região de tórax e crânio. As lesões de entrada nomeadas pela letra "E"; lesões de saída, letra "S"; e projéteis, letra "P", são explicadas em detalhes na sequência.

A região do tórax do periciado apresentava as perfurações de entrada mais significativas denominadas como "E2" e "E3" (Figura 4). A região posterior do úmero apresentava a lesão "E1". Assim, o projétil número 1 (P1), responsável pela fratura de úmero, transfixou o braço em sentido póstero anterior - saindo na região do bíceps (S1) e reentrou na borda do peitoral esquerdo (E2). Este mesmo P1 foi responsável pela fratura da clavícula esquerda indicando a possibilidade de que a vítima tenha levantado o braço à altura do rosto, caracterizando sinal de defesa, pouco antes de ser atingido. Este projétil (P1) não foi localizado, pois se fragmentou em diminutos pedaços distribuídos ao longo do tórax, o que inviabilizou sua recuperação. 0 projétil número 2 (P2) também atravessou o braço esquerdo, sentido póstero anterior, e foi encontrado alojado pouco abaixo da articulação do ombro, sendo recuperado pela equipe. Ainda, foi observada uma terceira lesão de entrada (E3) no gradil costal esquerdo abaixo da axila. Este projétil (P3) rompeu o quarto gradil costal e se fragmentou totalmente, impossibilitando sua recuperação.
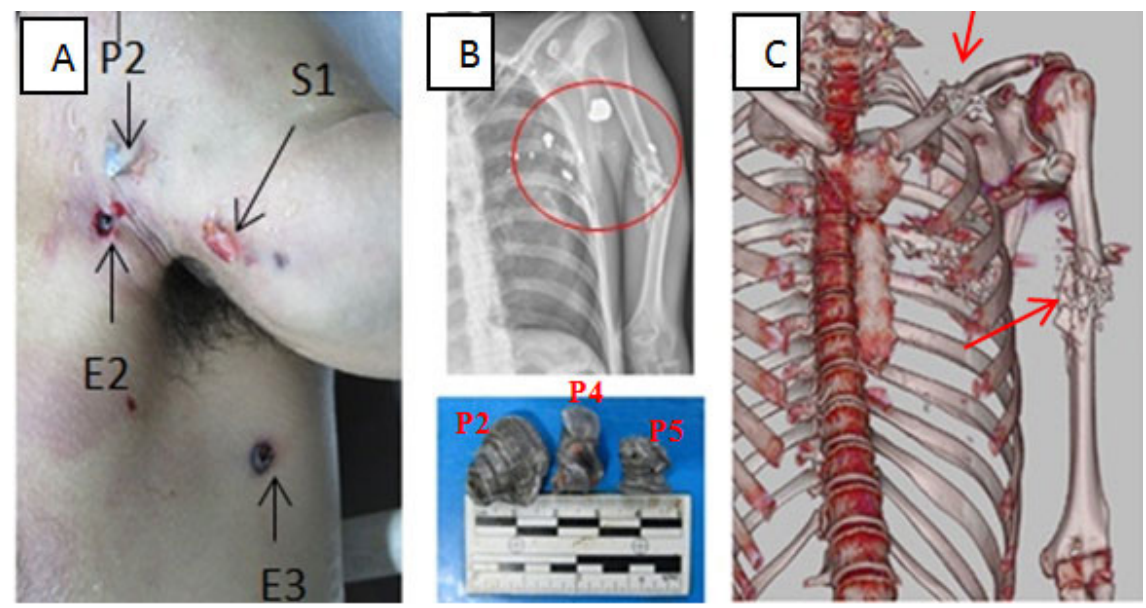

Figura 4: Da esquerda para a direita: em "A", fotografia da região de algumas lesões de entrada e saída; em "B", radiografia do hemitórax (dentro do círculo, elementos radiopacos, sendo o maior deles, o projétil P2). Abaixo da radiografia, imagem dos três projéteis que foram recuperados. Na imagem "C", uma reconstrução em VRT ilustrando as fraturas cominutivas no úmero e clavícula esquerda indicadas pelas setas (Fonte: Arquivo do setor de Radiologia Forense IML/BH).

As fraturas nos arcos costais não estavam tão evidentes para a equipe de necropsia, antes da abertura da cavidade torácica. Após a obtenção das imagens tomográficas, foi possível observar, além dessas fraturas, a presença de pneumotórax causado pela lesão do P3 que só pode, de fato, ser observado antes da abertura da cavidade. As reconstruções nos planos coronal e sagital permitiram, ainda, determinar a localização exata dos projéteis e sua relação com as estruturas anatômicas. Aspectos esses que podem ser observados na figura 5.
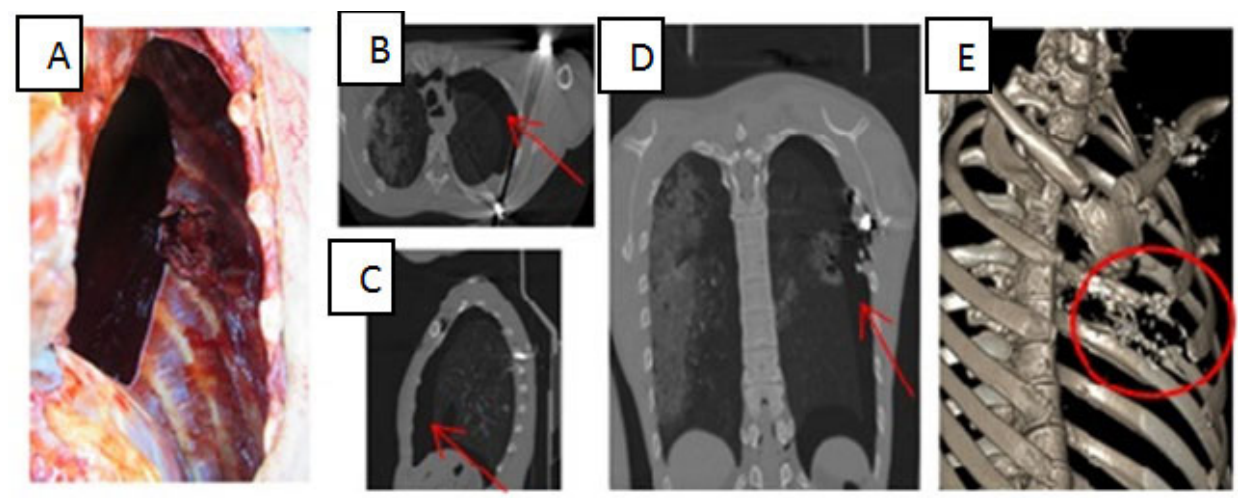

Figura 5: A imagem "A" mostra fotografia da caixa torácica aberta com presença de hemotórax abundante e fratura de arcos costais. No centro, em "B", "C" e "D", reconstruções multiplanares de TC, respectivamente nos planos axial, sagital e coronal, evidenciando pneumotórax (setas) do lado esquerdo. A letra "E" apresenta reconstrução VRT evidenciando fraturas em gradil costal esquerdo

(Fonte: Arquivo do setor de Radiologia Forense IML/BH). 
Na sequência, já na figura 6, foram avaliadas lesões resultantes de outros dois disparos, sendo um na face - borda lateral da órbita esquerda (E4) - e um no pescoço, mais precisamente na base inferior da cartilagem tireoide (E5). Ambos os projéteis ficaram alojados no cadáver: o projétil P4 na região occipital do crânio e o P5 na região posterior do pescoço, sendo que os dois foram recuperados. A figura também demonstra a reconstrução 3D com sobreposição de filtros para osso e tecidos moles onde é possivel identificar a fratura no osso frontal causada por P4. Os projéteis foram encontrados completamente deformados. Esse fenômeno é normal, tendo em vista que os projéteis são compostos de chumbo, relativamente maleável ao impacto.
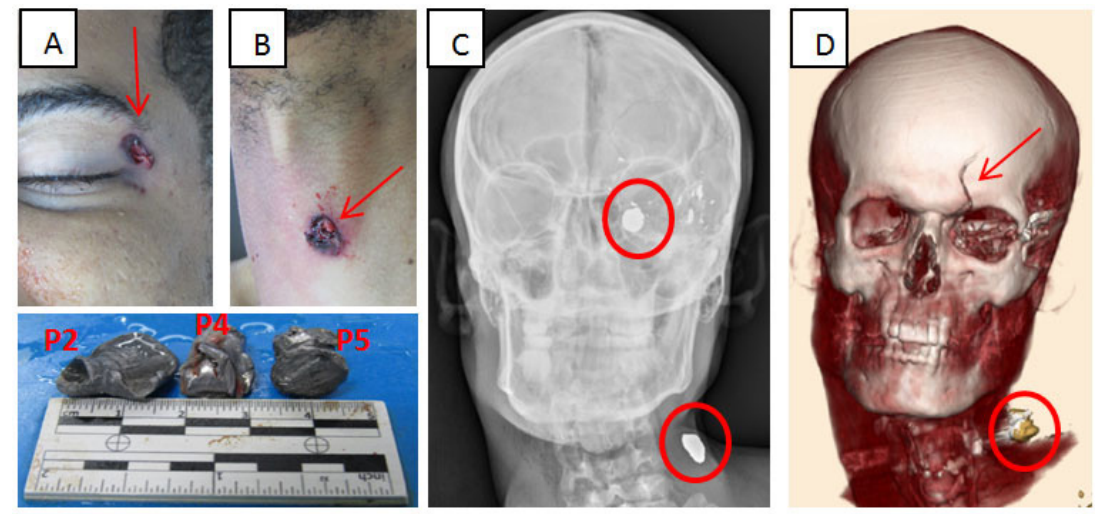

Figura 6: A imagem "A" mostra orifícios de entrada dos disparos (E4), enquanto que em "B", a lesão de entrada (E5). Abaixo, os três projéteis recuperados pós-necropsia. Ao centro, na imagem "C", radiografia do crânio anteroposterior demonstrando projéteis (P4 e P5) circulados em vermelho. Na letra "D", reconstrução 3D do crânio com sobreposição de filtros para parte óssea, muscular e objetos metálicos evidenciando fratura na região frontal que não havia sido bem visualizada na radiografia (seta), e P5 no círculo mais abaixo (Fonte: Arquivo do setor de Radiologia Forense IML/BH).

A utilização das ferramentas de edição de imagem, próprias do software do tomógrafo utilizado, permite a visualização de diferentes estruturas na mesma imagem. Na reconstrução $3 \mathrm{D}$ do crânio, por exemplo, foi possível identificar a trajetória do projétil dentro do crânio, a dimensão do dano causado e as lo- calizações exatas de P3 e P4. Também foi possível visualizar a presença de fragmentos milimétricos denominados "calda do cometa" por meio do filtro de sobreposição da radiografia e objetos metálicos, como demonstrado na figura 7.
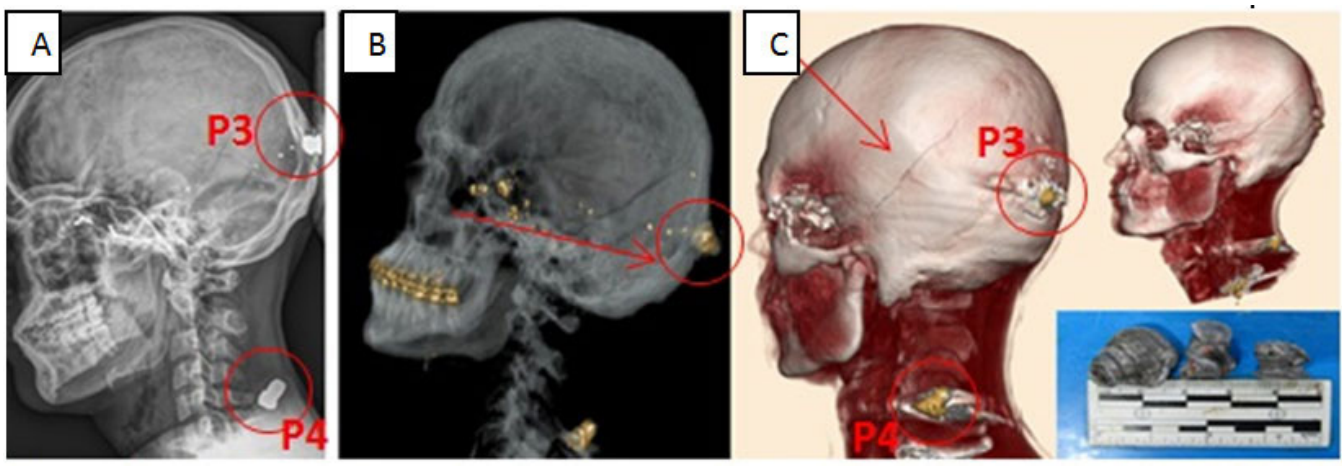

Figura 7: Observa-se em "A", radiografia de perfil do crânio mostrada na figura 1: apesar de P3 e P4 estarem bem visíveis, evidenciados pelos círculos, nota-se que os fragmentos metálicos menores não são bem visualizados, como em "B" que se trata de reconstrução em 3D com sobreposição de filtros de radiografia e objetos metálicos. Fica evidente o rastro de fragmentos metálicos

(calda do cometa) deixados por P3 determinando um trajeto em sentido antero-posterior. A letra "C" mostra reconstruções com sobreposição de filtros (tecido muscular + tecido ósseo + objetos metálicos) ilustrando a fratura linear em região parieto-occipital esquerda (seta), além de P3 e P4 alojados em região subcutânea (círculos) (Fonte: Arquivo do setor de Radiologia Forense IML/BH). 
As reconstruções realizadas, tanto pelas técnicas multiplanares como pelas técnicas em 3D, mostraram, logo de início, uma superioridade na qualidade das imagens produzidas em relação às radiografias convencionais. Importante destacar que os exames radiológicos são estudos complementares que objetivam compor o laudo pericial com ilustrações que permitem maior embasamento do relato médico sobre as lesões e causa da morte. A partir do caso exposto, segue-se discussão sobre a relevância da aplicação da radiologia forense em casos de homicídio por arma de fogo e uma análise crítica dos dois métodos: radiografias pelos sistemas digitais (imagens em 2D) e exames em tomografia computadorizada pelas reconstruções multiplanares e reconstruções em 3D.

A localização de projéteis de arma de fogo - a técnica de rastreamento radiológico

A partir da localização e da recuperação de projéteis - ou elementos balísticos - nos corpos necropsiados, é possível a realização de um confronto balístico por peritos forenses. Trata-se de uma técnica que permite afirmar, com determinado grau de certeza, que um projétil removido de um cadáver foi propelido, de fato, de uma arma de fogo questionada ${ }^{3}$. Quando um projétil é deflagrado, ficam impressas ranhuras em sua estrutura que são adquiridas durante a passagem pelo cano da arma. Se o conjunto das estrias existentes no projétil recolhido de um cadáver, quando confrontado, for semelhante ao conjunto existente em um projétil disparado por uma arma conhecida, a perícia criminal estará habilitada a afirmar que o projétil analisado foi propelido pela arma questionada ${ }^{3}$. Contudo, localizar projéteis da arma de fogo em vítimas fatais não se constitui em tarefa fácil. Ao penetrar o corpo humano, os projéteis tendem a sofrer desvio de trajeto. Podem, ainda, se fragmentar ou entrar em estruturas tubulares sendo, assim, localizados em sítio muito diferente da lesão de entrada ${ }^{1}$ como pode ser observado no presente caso relatado.

Este trabalho de localização e recuperação dos projéteis envolve uma equipe de profissionais que, no caso do IML/BH, geralmente é composta por dois auxiliares de necropsia, um médico legista, um técnico em radiologia e um escrivão de polícia. Todos servidores da Polícia Civil de Minas Gerais, cada um dentro de suas atribuições específicas, em um trabalho transdisciplinar cuja finalidade é produzir um laudo médico legal mais robusto. Todos os casos de morte violenta são periciados por uma equipe multidisciplinar. Dentre os mais rotineiros, estão os casos de homicídio. Nas perícias de homicídios por arma de fogo, é necessária a construção de um "mapa de lesões" que é um esboço esquemático onde se mostra a localização de lesões de entrada e de saída dos projéteis. Vítimas de múltiplos disparos configuram um quadro ainda mais complexo na construção deste mapa $\mathrm{e}$ na remoção dos projéteis. Assim sendo, os exames radiológicos, sobretudo os de TC, auxiliam o médico legista e 0 auxiliar de necropsia na construção do mapa, reduzindo o tempo da perícia.
É atribuição da equipe de radiologia do IML/BH produzir imagens radiográficas de todos os casos de homicídio por arma de fogo, evidenciando a localização dos projéteis para que possa ser removido e encaminhado para o confronto balístico. Seguindo este objetivo, trabalham com o conceito de "rastreamento radiológico" que consiste em tomadas de radiografias panorâmicas sequenciais incluindo estruturas ósseas e tecidos adjacentes ${ }^{4}$. A rotina para os casos de homicídio abrangem sempre tomadas radiográficas em dois eixos de crânio, tórax, abdome e pelve antero posterior e lateral - no intuito da localização dos projéteis. Neste sentido, a utilização de equipamentos de radiologia de baixo custo, como os convencionais, equipamentos com tecnologia $\mathrm{CR}$ ou mesmo DR, se comparados a equipamentos de alto custo, como TC, devem ser avaliados e problematizados do ponto de vista de vantagens e desvantagens.

\section{CONSIDERAÇÕES FINAIS}

Os equipamentos de raios- $x$, sobretudo os digitais, permitem aquisição rápida dos exames. Essas imagens realizadas em dois eixos já auxiliam, de modo significativo, no estudo de casos de homicídio. $O$ custo do equipamento, instalação e contratos de manutenção são também fatores positivos, se comparados com equipamentos de TC. Entretanto, os aspectos que envolvem a perícia de um indivíduo baleado, como os padrões de fraturas secundárias, o trajeto do tiro, a localização exata de projéteis e de pequenos fragmentos podem não ser muito bem evidenciadas nas radiografias, sobretudo se os sistemas utilizados forem convencionais que envolvem filmes radiográficos e processos de revelação. Além disso, a dificuldade de posicionamento do cadáver devido ao estado de rigidez, ou decomposição, pode gerar sobreposição de diversas estruturas que prejudicam a análise das imagens, como demonstrado no caso em tela. Uma terceira desvantagem está associada aos fatores de distorção da imagem. A imagem projetada no receptor nunca possui a dimensão real do objeto devido aos fenômenos da distorção definida por Bontrager $(2003)^{6}$, como "a representação equivocada do tamanho do objeto, ou da sua forma, quando projetada no meio de registro radiográfico". Esta distorção sofre variações de acordo com a distância do objeto ao receptor, da angulação da ampola e também da divergência dos feixes de raios- $x^{7}$. Na prática, o que acontece devido a este fenômeno é que os projéteis nunca estão exatamente nos lugares em que apareceram nas radiografias.

A aplicação da TC, por sua vez, apresenta as desvantagens do alto custo do equipamento, além de demandar conhecimentos técnicos mais avançados por parte dos profissionais envolvidos. Os tomógrafos modernos multidetectores podem escanear o corpo inteiro de um indivíduo em poucos segundos. A imagem resultante da tomografia é um corte anatômico do corpo, sem a sobreposição de estruturas, com alta diferenciação de tecidos e, por se tratar de uma imagem digital, pode ser manipulada pelo operador para diferentes aplicações, como reconstruções 
multiplanares e 3D ${ }^{8}$. Assim, concluiu-se que a utilização da TC em casos de homicídio por PAF, como o presente caso relatado, se mostrou superior aos equipamentos de raios- $x$ em função de três fatores principais: 1- possibilitou a localização mais precisa dos projéteis e fragmentos; 2- permitiu a descrição exata das lesões internas causadas pelos projéteis; 3- eliminou os problemas de sobreposição de imagens frequentes nos exames de raios- $x$. Desta forma, o pós-processamento de imagens permitiu produzir imagens em 3D com uma série de sobreposições de filtros que possibilitaram melhores ilustrações do caso.

\section{REFERÊNCIAS}

1. Brogdon G. Forensic Radiology. 2. ed. CRC Press; 2011.

2. Dirnhofer R, Thali MJ, Vock P. The virtopsy approach. 3D optical and radiological scanning and reconstruction in forensic medicine.
1. ed. CRS Press; 2009

3. Oliveira SF, Kock HA, Almeida CAP, Gutfilen B. Participação da Radiologia nas perícias necroscópicas de baleados realizadas no Instituto Médico-Legal do Rio de Janeiro. Radiol Bras. 2005;38(2):121-124.

4. Sá LL, Souza GC, Mendes LM. Aplicação da Radiologia Forense no IML/BH. Revista CML. 2019;4(1):16-23.

5. França GV. Medicina Legal. 10. ed. Rio de Janeiro: Ed. Guanabara Koogan; 2011.

6. Bontrager KL. Tratado de Técnica Radiológica e Base Anatômica. 5. ed. Rio de Janeiro: Guanabara Koogan; 2003.

7. Biasoli AJ. Técnicas Radiográficas: princípios físicos, anatomia básica, posicionamento. Rio de Janeiro: Rúbio Editora; 2006.

8. Mourão AP. A tomografia e sua evolução. In: Mourão AP. Tomografia Computadorizada: Tecnologias e aplicações. São Paulo:

Editora Difusão; 2007. 